Portland State University

PDXScholar

\title{
The Impact of Domestic and Foreign Forces on Guatemala's Social Services
}

Brooke Marie Reichert

Portland State University

Follow this and additional works at: https://pdxscholar.library.pdx.edu/honorstheses Let us know how access to this document benefits you.

\section{Recommended Citation}

Reichert, Brooke Marie, "The Impact of Domestic and Foreign Forces on Guatemala's Social Services" (2018). University Honors Theses. Paper 591.

https://doi.org/10.15760/honors.600

This Thesis is brought to you for free and open access. It has been accepted for inclusion in University Honors Theses by an authorized administrator of PDXScholar. Please contact us if we can make this document more accessible: pdxscholar@pdx.edu. 
The Impact of Domestic and Foreign Forces on Guatemala's Social Services

By:

Brooke Marie Reichert

An undergraduate thesis in partial fulfillment of the requirements for the degree of Bachelor of Arts

in

International Development Studies.

Thesis Advisor:

Evguenia Davidova, $\mathrm{PhD}$.

Portland State University

2018 


\begin{abstract}
:
This thesis will look at the socio-political history in both domestic and international contexts to analyze the development of Guatemala. This work will evaluate the positive and negative impacts of foreign aid and intervention in the development of Guatemala. International development theory is applied to this case study to better understand the current health and education crisis that intensified after the Cold War era. This thesis will serve to answer the following questions: how have internal and external forces shaped, beneficially and negatively, the current state of human development and social services in Guatemala? Why has Guatemala, a resource rich nation, been unable to secure basic rights for its citizens, as seen in the current high levels of disease and illiteracy? To answer these questions, this thesis will connect Guatemalan history to national development and place its development in an international context. Critical analysis and comparative research methods are used to create a more holistic picture of Guatemala's development history. Evidence presented in this thesis comes from academic articles, governmental documents, and studies from multilateral aid organizations.
\end{abstract}

\title{
Acknowledgements:
}

First and foremost, I would like to extend my greatest gratitude to my thesis advisor Professor Evguenia Davidova for her thoughtful contributions during all of our meetings. I appreciate her dedication to my work throughout this undergraduate thesis process. I would also like to thank the professors in the International and Global Studies and Applied Linguistics departments for all that they have taught me. Last but not least, I would like to dedicate my thesis to my family, partner, and best friend. Thank you all for supporting my journey in education. 


\section{INTRODUCTION AND RELEVANCE:}

My studies in international development and about Latin America have led me to question the discourse around modern development and foreign aid. I have taken multiple classes at Portland State University which detailed the complex social and political history of Guatemala and I chose my thesis as an opportunity to further investigate Guatemala's development. Guatemala is both an anomaly in the region and an example of the trends in Latin America. Guatemala's interesting position, as both unique and exemplary, is the reason it is chosen as a case study for this thesis. This research was prompted not only by my curiosity about Guatemala's development, but also a desire to better understand the development history that has led to modern development obstacles. I hope to teach English as a foreign language in Latin America in the future, but I first would like to understand the region's history and current development trends. I would like to improve my language skills so that I can propel the trend of multilingual education systems which increase communication and make education more accessible. I hope to work in a school in Guatemala after graduation, but would first like to deeply understand the development of social services in the nation before working in the education system there. My personal investigation into the development history of Guatemala has led to a revealing of many trends that are described in the following thesis. The goal of this thesis is to investigate the history behind Guatemala's development and create a well-rounded picture of the factors that have led up to modern development. In this thesis, I will also critique the motivations and roles of international players in Guatemala's development scene.

International development is an interdisciplinary field within the social sciences. Development scholars analyze development through a variety of disciplines including anthropology, political science, history and economics (see Figure 1). Due to the complex nature 
of the field, development as a concept is often defined differently by scholars and professionals working in international development. Many academics agree that there are multiple factors which influence the development of a nation state; including but not limited to politics, the economy, the environment and social factors including education. Modern development agencies and nations often see income as the primary means of development while finances are not the only goal of global development. Within this economic perspective, the goal of development is high levels of national income which is measured by gross domestic product (GDP), gross national product (GNP), and gross national income (GNI). These financial measurements result in projects with economic growth as the end-goal of development.

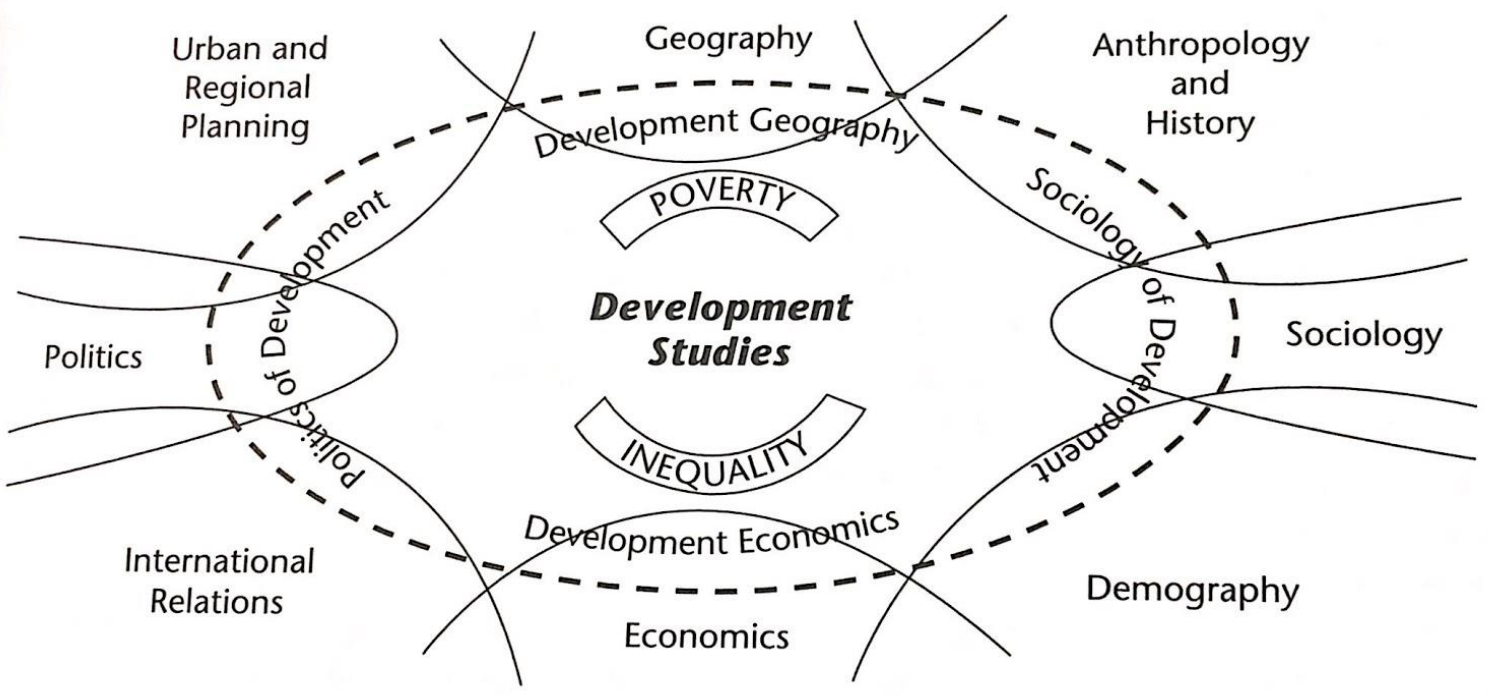

Figure 1: Diagram of the interdisciplinary nature of development studies. Source: The Companion to Development Studies by Vandana Desai and Rob Potter. $3^{\text {rd }}$ Edition (Routledge, 2014) 
While some professionals and academics believe high income is the end goal of global development, others disagree and suggest that global development means a higher standard quality of life. According to studies completed by anthropologist Tracy Bachrach Ehlers, women in traditional communities are often negatively impacted by business ownerships. Ehlers' research has shown that development based on economic criteria may have poor consequences for women, as employment frequently means less educational opportunities for women. Her research shows that economic growth may not necessarily mean equality, especially for female populations (Ehlers). Variations in the definition of development change how governments and organizations implement development programs and goals. The dominant ideology in development discourse has an impact on funding and program implementation. An economic perspective has led to a focus on financial development- but has this been a successful measurement of development? An economy-based development model cannot capture the full picture of social wellness and access to basic rights. Some scholars, such as Amartya Sen in his book Development as Freedom (1999), argue that the focus in development should be placed on human development and wellbeing instead of financial wealth. Sen's writings marked an important shift in development theory which began including important markers of development beyond capital and growth of wealth.

My work will analyze the role of foreign aid and challenge the traditional Western perspective of development and foreign aid, which often follows W.W. Rostow's Modernization Theory. In Modernization: Stages of Growth (1960), W.W. Rostow described five stages of economic growth that all nations must go through to become developed. Rostow based all stages of growth and his linear trajectory on the development of the United Kingdom (Lemert). His theory perpetuates the idea that the West serves as a role model and that developing nations must 
follow suit after Western Europe and the United States. There are a multitude of problems in western development as seen by wealth disparity and unsustainable development trends. The current state of developed nations should be, and is not, a goal of developing nations.

Modernization was a dominating theory in the development field for decades, but the discourse about development has shifted. Developing nations, in contrast to Rostow's theory, hold their own stories and trajectories that do not simply follow behind the West.

Development, instead of being a linear trajectory as Rostow described, is a complex and evolving system of interrelated domestic factors and international relationships. My thesis will serve as evidence against the western-biased trajectory theory that has dominated the development discourse until recently. This thesis will instead work with the World systems theory which argues that nations are not set on an equal playing field and do not have the same end-goals. Immanuel Wallerstein contradicted the modernization trajectory and instead divided the world economy into three categories including the core, semi-periphery, and the periphery in his World systems theory. According to Wallerstein, the world-economy is divided into a hierarchy in which some nations receive more rewards and benefits than others. In this theory, Wallerstein asserts that nations in the core benefit from the exploitation of the nations in the periphery and semi-periphery and that this makes it more difficult for nations in the periphery to achieve the same development (Lemert). Nations may shift in and out of categories, but this theory argues that core-state nations benefit from the periphery and keep the periphery out of the core through hegemonic powers. Wallerstein's theory best explains the relationship between the United States and Guatemala, as this thesis will argue. This thesis shows that the story of developing nations includes more factors than only financial wealth as development theories have described in the past. Development theory and application is critical to the manner in which 
development goals and projects are created and implemented by both national governments and aid agencies; these theories directly impact international relations and the progress of human development in developing nations.

\section{METHODOLOGY}

This work was completed by comparing and analyzing research from multiple sources including governmental documents, studies completed by multilateral aid organizations, private sector aid findings, and academic research. My analysis includes evidence from primary and secondary sources and I use both qualitative and quantitative evidence to support my assertions. In my work, I apply a theoretical model of development from Immanuel Wallerstein to the case study in Guatemala. The complexity of a whole nation's development cannot be synthesized in one undergraduate thesis, but this thesis works to provide a more holistic picture of Guatemala's development than is often considered in development projects and organizations.

\section{DEMOGRAPHICS AND HISTORICAL CONTEXT}

Guatemala is a resource rich nation with fertile agriculture land that bears a variety of primary commodities. Guatemala is well known for its banana production, which is highly involved in the global market economy. Guatemala is the largest nation in Central America and one of the countries with the biggest Indigenous populations in Latin America (Chase-Dunn, 109 and Abate, 6). Guatemala's population in 2017 was 15,460,732 and the Maya make up 39\% of the total population (World). The majority of the population (60 percent) is people from Ladino, or Spanish, backgrounds (World). Part of the population is made up of Mestizo Guatemalans who are of both Indigenous and European (primarily Spanish) descent. Mestizo populations are 
sometimes counted with European populations and sometimes with Indigenous populations; the CIA World Fact book includes Mestizo populations with the Ladino population (World). According to the Pan American Health Organization (hereafter PANO), there are many Guatemalan Indigenous groups including the Garifuna, the Maya, the Xinca, and Mestizos (Country). While there is some dispute on population statistics regarding Mestizo groups, these figures give an idea of how many Guatemalans are Indigenous. Despite making up a significant portion of the Guatemalan population, Indigenous Guatemalans face extreme inequality and lack access to basic rights.

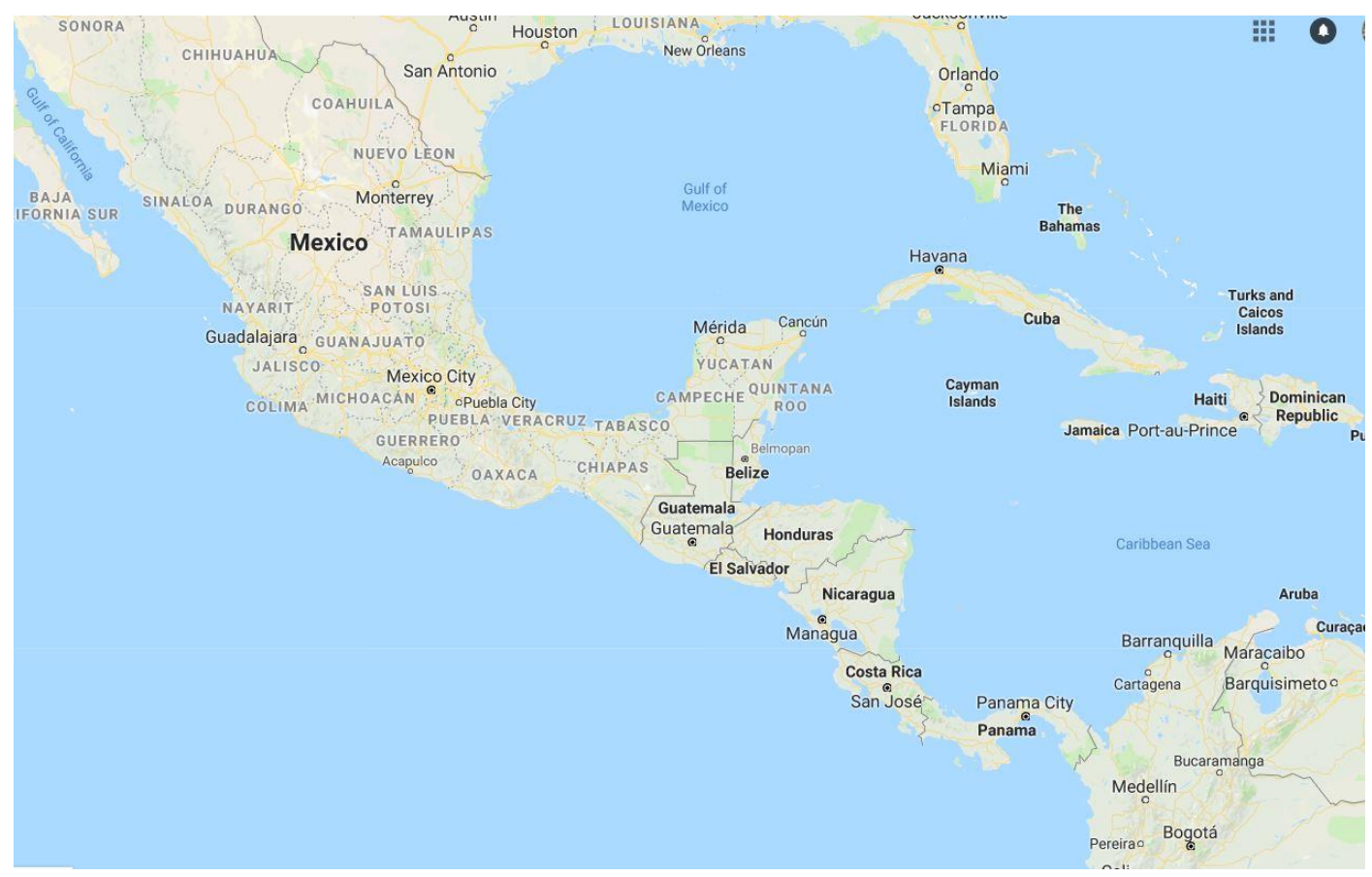

Figure 2: Map featuring Central America shows the location and size of Guatemala. Source: Google Maps.

While Spanish is the official language of Guatemala, there are also more than 22 Indigenous languages and dialects spoken by Guatemalan citizens. Many Indigenous citizens are monolingual in their native language and do not speak Spanish (Country). Additionally, many 
officials and professionals are monolingual in Spanish and this is a barrier for Indigenous people participating in health services and education. Some scholars confirm these divisions and state that "very few social protection policies exist that are differentiated and specifically targeted to Indigenous people" and this is a problem because Indigenous populations have the most disadvantages of any Guatemalan demographic (Hall and Patrinos, 3). There is a proven disparity between Indigenous and non-indigenous populations, yet Guatemalan legislation is not successfully addressing this divide.

Like most other nations in Latin America, Guatemala's history includes conquest and colonialism, along with a history of post-independence intervention. Christina Abate notes that the Spanish conquered Guatemala in the 16th century and it did not gain independence until 1861. The post-independence era has not resulted in equal basic rights and the small Ladino (non-indigenous) population still holds most of the national power. The structural inequality from colonial days have continued into modern times and there are still extreme inequalities in income and land ownership distribution; 64 percent of Guatemalan land is owned by two percent of the population. 50 percent of the population is in poverty and 15 percent is in "extreme" poverty (Abate, 7). The legacies of colonialism have continued into current times and are reflected in the disparities between the Indigenous and non-indigenous.

While Guatemala is defined by the World Bank as a nation with low to middle level income (according to GNP per capita), the income inequality among citizens is startling. Guatemala faces issues of underemployment, poverty, and conflict between ethnic groups. Despite the middle level income status, Guatemala has outstanding levels of illiteracy and high rates of disease (Chase-Dunn, pg. 109). These rates are especially high for Indigenous populations and particularly for Indigenous women. Socio-political and economic factors have 
culminated over the past 70 years in Guatemala, especially during the Cold War era, to create severe national inequality. A culminating divide in rural and urban populations has grown since the Cold War era and has contributed to the issues seen in Guatemala's social services.

Guatemala serves as a very interesting development case study for a variety of reasons. Guatemala has seen a large amount of intervention and manipulation by foreign organizations and governments that have had a significant impact on its development history. There is an array of domestic factors that have had direct impacts on the development of social services; these range from geographic factors and linguistic variation among citizens to the decades of political violence suffered by civilians. Guatemala is both unique in its national story and simultaneously exemplary of Latin American policy and development. Similar to many other nations in Latin America, Guatemala faced conquest by European powers in the 1500 s and intervention by the United States during the Cold War era. Despite a similarity to other nations in the colonial and intervention history of Latin America and having natural resources available, Guatemala stands out from all other on the continent by having the lowest rates of access to important health care and education services. Guatemala is an outlier in rates of inequality, health diseases, and illiteracy for the Western hemisphere; this is especially the case for women and Indigenous populations. This paper analyzes the factors that have led to the great inequality in social services and works to place the context of these issues in the global development picture.

\section{THE CIVIL WAR AND U.S. INTERVENTION}

In a survey of the policy that the United States has taken towards Guatemala, the U.S.Guatemalan interactions can be seen as far less than beneficial. Despite a claim to help developing nations, U.S. foreign policy in Latin America and Guatemala particularly can be seen 
as self-serving and consequential for developing nations. While the appearance of modern trade markets and foreign aid between the U.S. and Guatemala may seem beneficial on the surface, the intentions and history behind these relations is rather bleak. Christopher Chase-Dunn states that "the actions of U.S.-based firms and political-military interventions at important historical points have had a major impact on Guatemalan society, as well as on other Central American countries" (Chase-Dunn, 110). Alike this thesis's argument, Chase-Dunn believes these interventions have created more problems than solutions for Guatemala. This thesis suggests that these interventions have been beneficial for the U.S. (the core according to World Systems Theory) and detrimental to Guatemala (the periphery). While the U.S. economy has benefitted from Guatemala's banana export economy, protected by military intervention, Guatemala has arguably not benefitted from this relationship. Moreover, Stephen Brown called the motivations of aid donors into question; stating that bilateral aid is often motivated by government's pushing their agendas and policy (Brown, 141). Historical and modern relations with Guatemala are arguably self-interested on behalf of the United States. U.S. businesses have greatly benefited from Guatemala while Guatemala has faced severe challenges in the wake of U.S. intervention. The challenges for Guatemala have included the underdevelopment of its economy, resulting ethnic conflict, and severe poverty levels. The U.S. military interventions, which left an intense aftermath for Guatemala, are the response to global Cold War policy in the 1950s.

The United States took stakes in Guatemala during the Cold War era when the 'Pink Tide' was sweeping across Latin America. In the Pink Tide, Latin American governments shifted towards more left wing governments. This did not fit with the U.S. agenda during the Cold War and we can effectively see the amount of interventions and 'aid' given to Latin America during this time as a proponent of U.S. foreign policy. This is prominently the case with the U.S. and 
Guatemala. Guatemalan President Jacabo Árbenz nationalized Guatemalan lands in the 1950s in a more left leaning political action; this presented a problem for U.S. fruit markets and foreign policy. This action impacted U.S. based United Fruit Company which owned a lot of land in Guatemala. In 1954, Arbenz was overthrown in a coup supported by the American Central Intelligence Agency (Shiffman \& Valle, 64). The U.S. has continually asserted global economic dominance with support from military intervention and interference in national governments.

In 1960, Civil War broke out between "U.S. trained counterinsurgency forces and leftist guerrillas" (Abate, 7). The Civil War lasted 36 years from 1960 to 1996 and spread across the nation into areas populated by Indigenous Mayan communities (Abate, 7; Shiffman \& Valle, 64). The war resulted in over 200,000 deaths; the majority of which were Indigenous civilians (Abate, 7). The war included waves of violence, or 'campaigns' which targeted Indigenous populations. Once such instance was the "scorched-earth" campaign or "la violencia" that took place from 1981 to 1983 and in which 100,000-150,000 people were killed (Abate, 7). The prevalence of ethnocide in the Civil War makes it easy to understand the patterns of inequality that exist in modern development. The Guatemalan Commission for Historical Clarification stated in 1999 that the national army was responsible for the destruction of 600 villages and $93 \%$ of the deaths in the civil war. Mayan school teachers were often targeted and killed by the Guatemalan army in the 1980s because it was believed the teachers were helping the opposing guerrillas. Abate writes that this produced fear around education and prevented development in rural education for many years (Abate, 7-9). We are able to see the direct impacts of intervention and civil war on the progress of human development, namely education and health care. According to Shiffman and Valle, there is a prevalent distrust of the government by Mayans due to the violence they suffered at the hands of the national military during the Civil War (Shiffman \& Valle, 65). This 
distrust of the state includes a reluctance to participate in both school systems and to receive services from government health care facilities (Shiffman \& Valle, 65).

\section{GUATEMALA'S HEALTHCARE SYSTEM}

Guatemala is one of very few countries in Latin America that has legislation with universal health care built into the Constitution, yet the nation also has startlingly high rates of disease and mortality. Despite having universal healthcare, Guatemala faces many domestic and global barriers to providing universal health care access. As Gillette Hall and Harry Patrinos point out, "legislation alone does not guarantee rights" (Hall and Patrinos, 2). This is a trend in Guatemalan development; despite progressive claims in legislation, national change fails to occur. The healthcare system in Guatemala has shown particularly high levels of inaccess for female and Indigenous populations; the lack of access reflects the severe disparity between Guatemalan populations. This national disparity is based on gender, ethnicity, class and locality.

With universal health care built into the national constitution, the Ministry of Health and Social Welfare (MHSW) is in charge of national health care. Unfortunately, the MHSW is often not effective due to politics and finances. The Guatemalan health system is described as "fragmented" and there are multiple "complex challenges" in the current health system that make it difficult to resolve the apparent health disparities. The PAHO reports that the language barrier is a main obstacle to achieving improved health care; since providers often do not speak Indigenous languages and Indigenous citizens often do not speak Spanish (Country). As observed by Hall and Patrinos, "indigenous people, especially women and children, continue to have less access to basic health services; therefore, major differences in indigenous and 
nonindigenous health indicators persist" (Hall and Patrinos, 8). The national health care system is functioning for certain population, namely urban Ladino populations, but continues to fail the rural and female Indigenous demographic.

The health indicators mentioned above present three significant trends in the health system including correlations between demographics, high rates of Indigenous female medical problems, and the connection between maternal and infant health. The first finding is a correlation between ethnicity, geography and health care. Studies from the PAHO found that the highest rates of maternal mortality were related to rural and Indigenous populations who faced physical barriers to healthcare access such as lack of roads and poor transportation to hospitals. The second trend in Guatemalan healthcare is the correlation between Indigenous populations and high rates of female disease and death. According to the PAHO, of the 2013 maternal mortality deaths 68 percent were indigenous women. Since Indigenous people make up half of the population, the maternal mortality rate for indigenous women should hypothetically be 50 percent of the death rate. This means there is an 18 percent gap in rates of maternal mortality. The third observable trend in the Guatemalan healthcare system is a connection between pregnancy health and birth delivery issues and high rates of infant death and disease. This is seen in the prevalence of infant death under the age of one due to disorders stemming from the perinatal period (meaning the weeks before birth) and congenital malformations (disorders which come before birth or during delivery). Amongst these three trends in the healthcare system there is a noticeable correlation between gender, ethnicity, maternal care and disease/death. These trends convey the health inequalities between ethnicities and gender. Statistics about the healthcare system show that there are staggering health inequalities according to the demographics of Guatemalan citizens. The following passage from the Indigenous Peoples, 
Poverty and Human Development in Latin America: 1994-2004 report from the World Bank corroborates the aforementioned healthcare trends:

Health indicators, ranging from maternal mortality to in-hospital births and vaccination coverage, are systematically worse for indigenous people. Underpinning this result is the fact that basic health care coverage remains a problem, particularly for indigenous peoples. For example, in all five countries health insurance coverage remains relatively low, failing to surpass 50 percent of the population. In three of the five countries (Bolivia, Mexico and Guatemala) coverage of indigenous families lags substantially behind that of the rest of the population. In virtually every basic health indicator indigenous people exhibit worse health outcomes. Among these, one of the most important gaps to emerge from this report may be the fact that indigenous children continue to exhibit extremely high malnutrition rates, another likely factor constraining learning outcomes. (Hall and Patrinos, 8)

The World Bank report cited in Hall and Patrinos reinforces assertions made about the healthcare disparity between Ladino and Indigenous populations. The trends in Guatemala's access are not limited to one or two diseases, but consistently show up across a spectrum of health issues. From maternal mortality and birth to nutrition, Indigenous people are repeatedly at a disadvantage. This passage from Hall and Patrinos also point out the intersectional nature in which health impacts education; students with malnutrition are unable to produce desired "learning outcomes". While coverage of Indigenous families is a regional issue, as seen in the passage with examples from Bolivia and Mexico, this is a particular problem for Guatemala as seen in national statistics. 
Further evidence for these trend claims comes from the Reproductive Age Mortality Survey (hereafter RAMOS) which was completed in 2000 and provides data on the rates of maternal mortality in Guatemala. According to RAMOS, the maternal mortality rate (MMR) is three times higher for indigenous women than non-indigenous women in Guatemala (Flores, 188). Indigenous women make up 48 percent of Guatemalan deliveries yet make up 78 percent of maternal deaths in Guatemala. This further proves that there is an unequal gap in the maternal health care received by indigenous women. Walter Flores writes that there appears to be a lack in access to services for Indigenous women and that Indigenous women are more likely to give birth in a non-hospital location. He emphasizes that only five percent of Indigenous Guatemalan women have cesarean births while $16 \%$ of non-indigenous women have cesarean operations. Cesarean births, according to Flores, can be considered an indicator of access to resources. Flores also writes that 50 percent of Indigenous women give birth at home without the use of a "qualified provider" while up to 85 percent of non-indigenous Guatemalan women give birth in a hospital. Indigenous women are both seeking and receiving fewer healthcare services as compared to non-indigenous women (Flores, 187-88). As visible in the maternal mortality rates, lack of maternal services results in more disease and death; this is not beneficial to human development and wellbeing. These levels of inaccess to government services show that there have been challenges to the health system in Guatemala that should be analyzed.

The PANO reports that solutions to the health care obstacles should connect the health care agenda to the economic and social agendas (Country). The PAHO states that the MHSW needs to work with other sectors to expand their capacity and overcome barriers to the current healthcare system (Country). Sectors may be able to increase their own capacities and achieve their agendas if they work with other organizations. Other development solutions to the health 
challenges are proposed later in the MOVING FORWARD section of this thesis. Overall, the Guatemalan healthcare system displays significant gaps in health services for Indigenous and female populations that have resulted in higher rates of disease and death. The healthcare trends described above are also prevalent in the national education system.

\section{ACCESS TO EDUCATION IN GUATEMALA}

Guatemala has some of the lowest education rates in all of Latin America and within the western hemisphere. The Peace Accords of 1996, signed after the Guatemalan Civil War, have attempted to improve national education after the end of the intense violence. However, the education system is still severely flawed when it comes to serving Indigenous populations. Despite including the Accord on Identity and Rights of Indigenous Peoples in the Peace Accords of 1996, Indigenous populations are underrepresented in the education system. While the government attempted to implement programs after the Accords, the education system has not improved due to a lack of resources, problems in management, and troublesome policies. Like the trends in health services, unequal rates in school enrollment and literacy in Guatemala are correlated with ethnicity and gender which perpetuate other social disparities such as income and health indicators. In Guatemala, only 68 percent of Indigenous males are literate and only 39 percent of Indigenous females are literate. Compared to a literacy rate of 77 percent for nonIndigenous females and 87 percent of non-indigenous males, these rates show a shocking gap between ethnic groups (Abate, 3-20). According to Hall and Patrinos, education quality and results are low for Indigenous students. This is highlighted by the fact that Indigenous students in Latin American countries receive lower scores on national reading and math tests and have higher rates of dropping out and repeating grades. The challenges faced by Indigenous populations are a result of "deep-rooted colonialism" and actions around "assimilation" despite 
the promises made about equality to Indigenous peoples in the Peace Accords (Hall \& Patrinos, 7). Abate asserts that the power of education can actually "be abused and used as a form of oppression" if the intentions behind education are askew (Abate, 5). While education is regarded as an inherent positive in the U.S.A, we need to consider the intentions and implications behind installing biased education systems. The legacy of colonialism is apparent in the education systems which favors non-indigenous students as seen by five common issues: language barriers, cultural insensitivity, geographic barriers and urbanization, gender norms, and fears by Indigenous families.

Language is a barrier in the Guatemalan education system due to the monolingual tendencies of teachers and students. Teachers tend to speak only Spanish while students often speak only Indigenous languages; this results in students being taught in Spanish rather than their native languages. There have been actions by the Guatemalan government to have schools in Indigenous areas, but there are still language barriers. Teachers who work in Indigenous areas are often Ladino and are monolingual in only Spanish. While some Mayan families feel it is helpful for students to learn Spanish, for academic and monetary reasons, others feel there needs to be more emphasis on Indigenous languages. In the 1980s, Spanish was not only required in the classroom, but students were actually punished for using their native language in class (Abate, 421). The difference in language is a significant barrier to increasing access to education across Guatemala, and is a barrier that has yet to be overcome.

Bilingual programs are increasingly popular in Latin America, however, these programs are not common in Guatemala. Hall and Patrinos state that even when "countries have implemented bilingual education programs, many of the programs have limited coverage, and some have inferior quality" (Hall and Patrinos, 2). Despite a regional attempt to create bilingual 
programs, the programs often lack the resources necessary for success. Abate argues in favor of investing in bilingual programs by stating that the cost of teacher training and new materials is actually balanced with the decrease in grade repeats; less grade repetition means room for new students and funding (Abate, 21). Bilingual programs may be a step forward for Guatemala, but the implementation of these programs is not abundant yet in Guatemala.

A difference in culture and lack of understanding for Indigenous culture is another hurdle in the Guatemalan education system. Abate argues that the government views education as helping Indigenous communities by pushing them towards the "modern, technologically advanced society", while really ignoring the values of these communities. According to Abate, there is a difference in curriculum between the Guatemalan government and Mayan peoples. Mayan culture focuses on family and community and prefers non-formal education which is part of daily life. This contrasts with the formal, standardized education that is taught in schools by a non-familial teacher. Mayan communities value "practical" education over textbooks and classrooms. While Mayan communities focus on experiential learning, the government emphasizes a classroom-based pedagogy. Additionally, textbooks are often insensitive to the Mayan culture and describe the Maya as a disappeared group which does not represent half of Guatemala's population (Abate, 11-15). This stark portrayal of culture are current obstacles to achieving education for all citizens.

Clothing is also an important cultural difference that impacts education rates. According to Abate, the Mayan traje (traditional dress) separates Mayans from academics who are thought to wear suits and ties. Mayans then face the issue of either being judged for wearing traditional clothing or for 'abandoning' their culture for suits and ties (Abate, 25). These cultural norms are a significant factor for Indigenous peoples seeking formal education. The Guatemalan 
government and western perspective of education may not be the right fit for Indigenous communities and this contradiction will continue to be an obstacle in the goals of the education system. The education system may need to become more inclusive to all cultures or may need to shift the goals of the education system itself.

Another obstacle in the way of education is the logistics of cost and transportation. Poverty and geography are key factors in access to education. Indigenous populations commonly live in rural areas which physically have less access to schools. Enrollment rates are correlated with a student's location because most schools are located in cities rather than rural areas. For rural students, travel to school may be costly in terms of both money and time- which could be spent working and earning money instead.. Multiple studies have shown that rural residency is correlated with lower rates of enrollment and completion of school. Research has also shown that income is a primary factor in education gaps. Studies say this is due to both expenses for school (transportation and materials) and due to the "greater household demands" that people in poverty face (Abate, 24-27). Costs in time and money are important indicators of whether or not children will attend schools.

Gender norms are a central factor in whether or not Indigenous girls will attend school. Familial perceptions of gender impact female enrollment in school. Girls may drop out of school after age 12 when they are thought to be needed for household work and reproductive roles in the home. Because females are considered so important for household roles, the cost of attending school may be perceived as higher for females than males. Completion rates for primary school is 10 percent lower for females than males. Females often leave school during the day to complete their roles in the home, such as cooking lunch for their families. Since these household roles hold such importance, females often drop out of school because it does not fit their roles in 
the home (Abate, 4, 25-27). The perceptions of gender in Mayan communities is part of the lower rates in formal education for female students.

The last trend observed in the barriers to Indigenous formal education involves the cultural anxieties and fears of Mayan families. Mayan parents may have experienced the punitive measures common in schools in the 1980s and not want the same experience for their children. Parents are often fearful that the attending school will mean "forgetting one's culture, language and history". This makes sense because the Guatemalan education system has not been historically beneficial to the Mayan culture. A lack in cohesion between Indigenous and nonIndigenous educational values warrants concern on the part of Mayan parents. Abate states that many Mayan parents also worry that their children will "be exposed to and learn bad behaviors" at the schools. Mayan parents may worry about swearing, smoking, and poor obedience after children attend school (Abate, 13). How can parents be expected to encourage enrollment in schools, if they have had such negative experiences about a school system that does not fit their cultural values? The dichotomy of values in the schooling system is a prevalent problem in the development of education. This opposition of Indigenous values and presentation of values in schools by the presiding Ladino majority is a lasting result of colonialism and has prevented cohesion and growth in the Guatemalan education sector.

\section{MULTILATERAL AND PRIVATE SECTOR AID ORGANIZATIONS}

Multilateral and private sector aid organizations often provide funds and services to developing nations. These funds and services can be very beneficial to nations, but they can also come at a cost. Several trends can be seen in large scale organizations which include top-down projects and the loss of government spending. The first issue with large organizations is the use of top-down development project applications. Multinational organizations may not consider the 
needs or desires of local people when designing and implementing development projects. While the organizations may consider their work as beneficial to local people, it may not be viewed this way from another, local perspective. Western culture and perceived development needs may be imposed on local cultures that do not have the same desires. While not the intention of aid organizations, large scale development projects may spread cultural imperialism from the West into developing nations. Top-down development projects may undermine the value of local knowledge and practices. While large organizations have helped with global health rates (such as vaccinations), we need to consider the agency of individuals and reflect on what is lost in the imposition of values on another culture.

The second trend in international aid organization is the interference in national programs. Organizations often focus on economic growth and perpetuate neoliberal policy models which may not be beneficial to national governments. Alexander Kentikelenis, Lawrence King, and Thomas Stubbs declare the relationship between the International Monetary Fund's structural adjustment programs and national public spending on health services as “controversial". In fact, a study from Van Hoeven and Stewart in 1993 found that the use of structural adjustment programs in Latin America led to a decline in public health expenditures in the period of 1981-1990 in 18 nations. Structural adjustment programs (hereafter SAPs), as part of debt relief, are part of foreign aid but they come with strings attached. With the revision of national policy, SAPs often lead to more neoliberal policies and cuts in social spenditures. While Kentikelenis et al admit the cuts in funding could possibly benefit civilians, they dispute the likelihood of this and admit that businesses and individuals probably benefit from neoliberal policies (Kentikelenis et al). While the use of loans and SAPs appears to help developing nations, they may in turn harm the development of social services. 
International organizations are unable to remain neutral and thus impose cultural beliefs and opinions on those being aided. While many organizations have agreed that nongovernmental organizations (NGOs) should remain neutral in conflict, this has not been the case. Taylor Seybolt writes that is very challenging for NGOs to remain neutral in conflict and in particular internal conflicts; Guatemala included. Military, political, and even social actions made by NGOs hold serious consequences for nations. Food aid provided to Guatemala has also arguably created dependency for civilians. NGOs can create positive change, but they can also play large roles in internal conflicts and this may not be beneficial to civilians (Seybolt). One can see how the destabilization of Guatemala by the U.S. and the created dependency on NGOs fits within Wallerstein's World System Theory of core and peripheral relations.

International organizations have been beneficial in providing financial aid and critical developments in technology to developing nations, but these benefits need to be evaluated with consideration for poor consequences. While intentisons may be to benefit developing nations, development projects may take away individual agency and promote west-biased culture. Organizational development may also promote neoliberalism and result in reduced healthcare spending. The roles of international organizations such as the UN, World Bank, USAID, and the IMF are more complex than simply providing beneficial help to developing nations, and this should be considered when reviewing the impact of their actions.

\section{MOVING FORWARD}

\section{Bottom-up Development}

An alternative to the top-down whole scale development projects that are applied by large organizations is local development which considers the needs of individuals and gives more 
agency within development. Local level development would be beneficial because citizens are able to advocate for their own needs and desires. Local development gives more freedom to individuals, whereas national or international development projects may be oppressive. This thesis argues that the end goal of development is human development and wellbeing. The examples provided about current development efforts show that these projects often have poor ramifications and do not result in social wellness. Grass roots organizations give more agency to Indigenous and female populations than what has been described throughout this paper. Asociación Ak'Tenamit is an example of an Indigenous run grassroots organization with very positive impacts on Guatemalan rural communities. Asociación Ak’Tenamit is a unique organization that was founded by an American citizen who visited Guatemala as a way to find out why so many of his U.S. employees (immigrants from Guatemala) sent remittances back home. The founder works on fundraising in the organization, but Asociación Ak'Tenamit is completely organized and run by Q'eqchi people. Projects in Asociación Ak'Tenamit include education programs, healthcare clinics, environmental projects, gender equality projects, cultural preservation projects, and income support. Asociación Ak’Tenamit is an example of a project that considers the needs and voices of the people it is serving. The PanMayan movement is another example of a movement that represents the needs of individuals. The movement strives to promote Mayan culture in a variety of mediums and is run by Mayan people (Abate, pg. 8). These movements are highly reflective of community needs and promote the desires of individuals, which often get lost in large scale aid projects. Bottom-up development may be a step in the right direction away from the issues seen in modern development. 


\section{Achievement as a Tool, not an End Goal}

Another possible direction towards future development will be the investment in social services for their inherent value. Many studies have shown the value and intersectional relationships between different social sectors. Authors Koch, Calhoun, Aracena, Gatica, and Bravo have found a high correlation between education level and maternal mortality rates and contraception rates for Chilean women (Koch et al). Koch et. al suggests that women's maternal health is dependent upon their educational level and not simply the financial and structural availability of healthcare services (Koch et al). Ilona S. Kickbusch, a political scientist involved in global health policy, cites the adult female literacy rate as "one of the 10 key indicators to assess women's well-being”. Additionally, education is correlated with women delaying marriage and childbirth, improved family care, and child education levels. Kickbusch writes that there has been a well-researched correlation between women's education level and fertility rates She suggests illiteracy as a contributing factor in inequality and the spread of disease. Women's education is an issue of human development as it is a strong indicator of death rates for children under the age of two years (Kickbusch). Abate writes that studies show investing in female education decreases childbirth and infant mortality, rates of HIV and AIDS, malnutrition rates, and rates of teenage pregnancy (Abate, 29). Not only does education decrease health issues, it boosts income and production in agriculture (Abate, 29). Development should not focus on individual sectors such as the economy, education, and health care. Instead, development projects should utilize the intersection of these sectors to promote all of them. The sectors can be treated, not only as end goals, but as tools in of themselves. 


\section{CONCLUSION}

The goal of this thesis was to provide a holistic analysis of the issues prevalent in the current development of Guatemalan social services. We can see the direct impact of the U.S. interventions and later Civil War on the development of social services including the education and health systems. Despite legislation calling for equality among Indigenous and nonindigenous rights, there has been a failure to provide basic rights to all Guatemalan citizens. There are a multitude of factors involved, but we can see several trends in each system. The healthcare system sees a lack of trust by Indigenous peoples which results in poorer civilian health, particularly among women. Language is a major barrier in the health care system and studies consistently show higher rates of disease and death for Indigenous peoples. We see similar trends in education including language barriers, issues with cost, cultural insensitivity, gender norms, and high amounts of fear. These factors all combine to create the failure in providing basic needs to Indigenous populations who make up half of the Guatemalan population. It seems that aid and intervention can be more beneficial to core countries than nations in the periphery, as shown in the case of the U.S. and Guatemala. Overall, development is not as simple as economic growth or applying the same actions as developed nations.

Guatemala has a complex history in development and this needs to be accounted for in any development goals and programs. Organizations cannot provide a blanket solution to the whole nation and expect positive results; we can see how this has not worked in Guatemala and can actually be very oppressive to citizens. Development projects should be carefully motivated and applied, as we can see how past actions have had distorted results on human development. Guatemala should be given more agency in its development in order to better serve the 
Indigenous populations that have faced a multitude of challenges throughout Guatemalan history. 


\section{Bibliography}

Abate, Cristina. "Guatemala's most Disadvantaged Group: Indigenous Mayan Females and Education.” Hofstra University, Ann Arbor, 2012. ProQuest, http://stats.lib.pdx.edu/proxy.php?url=http://search.proquest.com/docview/1034283820?a ccountid=13265.

Bjørgen, Katherine. "Women's education levels and its impact on their attitudes towards children's health development." Early Child Development and Care, vol. 181, no. 1, 10 Nov. 2009, pp. 73-87., doi:10.1080/03004430903262896.

Stephen Brown, "National Development Agencies and Bilateral Aid," in Paul Haslam et.al., Introduction to International Development, Oxford University Press, New York: NY. 2009, pp. 135-151.

Burton, Leone. "Education and Development." British Journal of Educational Studies, vol. 17, no. 2, 1969, pp. 129-145. JSTOR, JSTOR, www.jstor.org/stable/3119256.

Chase-Dunn, Christopher. "Guatemala in the Global System" Journal of Interamerican Studies and World Affairs, Vol. 42, No. 4, Special Issue: Globalization and Democratization in Guatemala, 2000, pp. 109-126, http://www.jstor.org/stable/166344

"Country Report: Guatemala", Pan American Health Organization, accessed 8 Feb. 2018, http://www.paho.org/salud-en-las-americas-2017/?page_id=127.

Ehlers, Tracy Bachrach. (2017). "Women Work Together: My Unforeseen Transition from Academic to Feminist Change Agent." Practicing Anthropology, vol. 39, no. 1, 2017, pp. 40-43., doi:10.17730/0888-4552.39.1.40.

Flores, Walter. "Inequity of Maternal Health in Guatemala." Tropical Medicine \&Amp; International Health, vol. 12, 2007, pp. 187-188.

Hall, Gillette; Patrinos, Harry Anthony. 2004. Indigenous Peoples, Poverty and Human Development in Latin America: 1994-2004. Washington, DC: World Bank. http://siteresources.worldbank.org/INTLAC/Resources/FinalExecutiveSummary_Eng May05.pdf.

Kentikelenis, Alexander., King, Lawrence., and Stubbs, Thomas. "Structural adjustment and public spending on health:

Evidence from IMF programs in low-income countries." Social Science \& Medication, vol. 126, 2015, pp. 169-176. <http://doi.org/10.1016/j.socscimed.2014.12.027>

Kickbusch, I.S. (2010). "Health literacy: addressing the health and education divide", Health Promotion International, Volume 16, Issue 3, 1 September 2001, Pages 289-297, 
https://doi.org/10.1093/heapro/16.3.289

Koch, E., B. Calhoun B., Aracena P., Gatica S, \& Bravo, M. (2013). "Women's education level, contraceptive use and maternal maternal mortality estimates". Science Direct, Public Health.

Lemert, Charles. (2004) "Social Theory: The multicultural and classic readings." Colorado: Westview Press, $3^{\text {rd }}$ edition.

Navarro, Vicente. "The Underdevelopment of Health or the Health of Underdevelopment." Politics \& Society, vol. 4, no. 2, 1974, pp. 267-293., doi:10.1177/003232927400400206.

Owen, Karen K, et al. "A Geographic Analysis of Access to Health Services in Rural Guatemala.” International Health., vol. 2, no. 2, 2010, pp. 143-149.

Sanford, Victoria. "The Blood of Guatemala-A History of Race and Nation.” American Ethnologist, vol. 28, no. 4, 2001, pp. 949-950.

Sen, Amartya. (1999). “Development as Freedom.” New York: Oxford University Press. ISBN: 9780198297581.

Seybolt, Taylor B. (1996) "The myth of neutrality.” International Affairs Peace Review. vol. 8, no. 4. pp 521.

Shiffman, Jeremy, and Ana Lucía Garcés del Valle. "Political History and Disparities in Safe Motherhood Between Guatemala and Honduras." Population and Development Review, vol. 32, no. 1, 2006, pp. 53-80.

Suarez-Orozco, Marcelo. “Learning in the Global Era”, Berkeley: U of California Press, 2007; ISBN: 9780520254367.

"The World Factbook: Guatemala." Central Intelligence Agency, Central Intelligence Agency, 14 Nov. 2017, www.cia.gov/library/publications/the-world-factbook/geos/gt.html. 